\title{
Study on the Application of Project-based Learning in Japanese Practical Teaching
}

\author{
Tianliang Deng \\ School of Foreign Languages \\ Dalian Neusoft University of Information \\ Dalian, China 116023
}

\begin{abstract}
The advanced engineering education concept of CDIO has great influence on the teaching reform in China. At the same time, the teaching reform of Japanese is constantly developing. Teachers use the learner-centered CDIO project teaching model to create a variety of scenarios that are professional in nature. Students can learn Japanese with the stimulation and nearly real situations, and they can make the language expression by the most direct communication. The author takes Japanese majors as the research object to elaborate the specific application of CDIO model in Japanese practical teaching. While affirming the study results, the author also explains the inadequacies and the corresponding strategies of Japanese practical teaching for solving the problems.
\end{abstract}

Keywords-project teaching; Japanese teaching; applied research

\section{INTRODUCTION}

The common feature of traditional Japanese teaching method is to understand the language and process language teaching from the perspective of the internal structure of language. The major task for foreign language teachers is to change the conceptions of education, improve the approach to Japanese teaching and train practical language talent. The core of the practical skills and the purpose of communication call for the attention of the circle of Japanese education. At the same time, Japanese education should also fulfill the society's demand for Japanese talent by continuously updating teaching methods, improving students' learning performances and meeting the needs of social development. Only in this way can students have an established place among the domain of employment. The cultivation of practical skills has become one of the important purposes of teaching reform.

\section{Project Teaching Practice Process}

\section{A. Pre-class Preparation for Project Teaching}

1) Preparation for the teacher's role:First of all, in the practical course of Jananese training, teachers should change their role of knowledge teaching to "coaching". The teaching mode in the CDIO project is essentially different from the traditional teaching theories that focus on grammar and vocabulary and take the form of infusion. The teacher no longer delivers monologues in the classroom. The principal task of the teacher is to create a real and meaningful language environment, adopt practical methods and help discover the purposes of the implementation for the students. Under the guidance of teacher, students will keep practicing in the corresponding language environment and ultimately, they will also analyze and solve problems according to the correct workflow, communication rules, and Japanese business etiquette. The teacher not only arranges and organizes the teaching plan, guides and participates in the student activities, but also evaluates and gives feedback according to performances of the students. Therefore, the teacher could not only be regarded as the instructor, but also the participant and organizer in the course of student's learning processes.

2) Preparation for teachers' tasks: The teacher introduces cultural background knowledge. The practice of students must be based on the cultural background. Learning Japanese is also learning Japanese culture, and the process of truly using Japanese is also the process of understanding and accepting the culture.

The teacher introduces the task of language practice. Students should be clear about the purpose of the exercise before practice. The more important the exercise is, the better the effect will be. Teachers should clearly assign tasks, set scenarios and put forward key points, and students can clearly understand the content, time, form and assessment standards of practice before implementation so as to achieve the goal.

The teacher introduces relevant knowledge. Although the teaching mode of the CDIO is mainly based on students' practice, it is also indispensable for teachers to explain the necessary knowledge. The cultivation of practical talent emphasizes "learning for application" and takes "use" as the standard of "learning". But without "learning", we cannot talk about "use", let alone "use it well".

The teacher coordinates students' activities. From the perspective of the characteristics of the CDIO project teaching mode, "Although teachers do not play the leading role, they are the soul of the whole teaching activity". Teachers should not only have organizational skills, but also have the ability of coordinating and responding to unexpected incidents, which requires the teachers to have 
sufficient experience and learning ability. Teachers no longer prepare teaching activities through the single thought of "teaching" by preparing lessons, but use multiple approaches to managing and coordinating the whole teaching activities, and teachers should have more knowledge and experience than what traditional teaching requires.

3) Preparation for teachers' teaching materials: The successful realization of the teaching purpose of CDIO education mode is based on the teachers' control of the overall teaching content and pace. The project of cultivating students' practical Japanese skills in enterprises should emphasize the creation of real and meaningful language environment and the use of language ability: that is, they can employ appropriate Japanese and business etiquette in a specific language environment. However, the use of language must be based on a certain cultural background, topic materials, rules and language materials. Therefore, it is necessary for the teachers to enlighten and guide students in this aspect.

Before teaching, teachers should first clarify the purpose of teaching and assessment standards. Then, the content, form and process of classroom activities are designed accordingly, and a series of relevant contents, such as relevant background knowledge and vocabulary elements, are taken into account to create a good language environment for students and help them make full preparations. Teachers should design more business-related scenarios for students to help them create more and more real Japanese application and practice opportunities. It is proved by practice that whether the teacher is fully prepared before class and whether the project design is realistic plays a crucial role in the smooth development of teaching. The use of authentic teaching materials is one of the most important factors to determine the effect of teaching. According to the teaching requirements, the created scenarios in the project and the prepared learning materials must be close to real life so that students can easily associate their own experience with the process of learning, which will be easy to accept. A study on educational psychology showed that no matter how much the teacher emphasizes the importance of a course, it is difficult to draw enough attention of the students, and only when they felt that the courses are associated with real life and help them solve the practical problems in life, will they pay attention and showinterest and determination to learn it well. CDIO's education model of teaching reform is precisely for the purpose of "learning for application". It mainly focuses on the cultivation of students' theoretical knowledge, professional skills and professional ethics.

4) Preparation of teaching facilities: It is best to design projects and display teaching materials and the activities of the introduction of background with the aid of multimedia classroom, where students can collect information and process information and watching courseware to expand their knowledge. This increases the efficiency of the classroom teaching, basically by sparing the blackboard writing. the class time saved can be used to strengthen inclass coaching and training. So it's better to have projectors installed in the classroom. Each student in our school has a laptop computer, on which they make full use of the network of multi-media classrooms. This computer-based environment provides convenience for promoting the teaching reform. At the same time, recording software is installed on student's laptops. The recording or video recording can also be used to evaluate their own practice and improve their Japanese grammar, pronunciation and application.

\section{B. Implementation of Project Teaching}

More than $95 \%$ of the students of Japanese start at university, most of whom start from scratch. The difficulty of teaching content elevates, step by step.

1) The teacher giving an introduction: The teacher gives a brief introduction according to the different teaching contents, aquainting the students with the teaching content and learning purpose for the purpose of arousing learning interest and paving the way for a readied learning mood.

According to the requirements of the course, the basic Japanese should be reviewed and consolidated step by step, such as the expressions of Japanese greetings, honorifics, self-deprecation, Japanese culture and Japanese business etiquette.

2) Creating scenarios: On the premise of the cultivation of practical skills, teachers should take into consideration the study of enterprise authenticity, language application, culture and etiquette in the scenarios created before class, and plan and design systematically.

3) Tasks assigned by teachers: Teachers clarify the class tasks and task assessment related instructions and points for attention. They explain the teaching situation and what should be paid attention to in this lesson, such as honorific and self-deprecating expressions in Japanese, using proper manners and addressing people. Also students should consider the work ethic of employees.

4) Group activities: The teacher groups the students by sex and performance in a manageable number, which facilitates the group activity and promotes the study as the goal. The teacher appoints a group leader who must have some leadership. The leader can also be elected among the students.

5) Students perform tasks: The group leader arranges the role assignment within the group, and the teacher participates in the guidance, including supervising the students' discussion and answering their questions, etc. the students need to Read the course book carefully while the group leader is responsible for the whole group, Students will Learn to play the role of the book. Then the teacher sets the scene to discuss. it is best for students to discuss and solve the problems in the designed scene with each other, Ask the teacher questions.students may need to ask questions about the language, Japanese culture and business etiquette, students may Read, and write the conversation on paper first, and it is possible for the students to discuss it 
in a group and gradually improve it such that they can eventually make presentations without reading any written manuscript, which makes their presentations close to natural and real communications. Teachers reconcile by participating in student activities and answer the students' questions in the activity and watch the students' overall progress.

6) Learning effect assessment: Students prepare and rehearse in groups after class before the presentation. The teacher evaluate their permormance In the form of individual report or group report. The teacher assesses, gives feedback and records academic performance according to evaluation criteria. At the same time, in order to arouse everyone's enthusiasm, both teacher evaluation and group evaluation are adopted as assessment methods.

7) Teacher's comments and conclusions: the teacher Makes a summary, guiding or enlightening the students according to the students' presentation and put forward Suggestions for improvement. The teacher Demonstrates the solution of the problem as necessary. The teacher, in the form of role-playing, evaluates the students in the form of "conversation assessment standard", encourages and corrects the students, and records the assessment results. Most of the group members can discuss with each other by reading the conversations in the texts and doing the study well.

8) Active use of students: The teaching effect is redone through presentation, revision, repractice, homework and other forms Feedback to check students' knowledge, including the accuracy and use of knowledge Properly. In the Japanese class, the teacher made more comments on the appropriateness of the use of Japanese and the acceptance from the other party; students need to pay attention to Japanese idiomatic expressions and relevant business etiquette, Japanese culture, Team work, etc.

\section{Final Performance Appraisal}

1) Content of examination: Previously the final examination laid particular stress on the test of knowledge, the results of which could not fully reflect the Japanese language application ability. Nor could they be used to provide valid feedback on class performance or to facilitate improvement., The conventional test is not comprehensive in terms of the evaluation of Japanese teaching effect. Cai Min points out, in contemporary student schoolwork evaluation of "comprehensive evaluation targets", that the basic evaluation of contemporary teaching goal by universal for "cognition, emotion and action skills" three areas: cognitive domain including knowledge, comprehension, application, analysis, synthesis and evaluation; The field of emotion includes the individualization of acceptance, reaction, formation, value concept, organization concept and value system. The areas of motor skills include perception, imitation, manipulation, elite action, coherent response, adaptation and action creation. "Only when teachers have a comprehensive understanding of the theoretical basis of the objectives of contemporary curriculum evaluation and establish evaluation standards for specific subjects can they make evaluation truly promote students' academic development". Therefore, this assessment content is also including students' field performance, psychological quality and professional ethics apart from language knowledge and application ability. Students' posture, vision, facial expression, etiquette, pronunciation and intonation, voice, speed and rhythm, communication strategy and other aspects are evaluated, so that students can become practical talents with communicational skills in the process of continuous evaluation.

2) Assessment method: According to the theoretical basis of student evaluation, the characteristics of foreign language learning and the training objectives of applied ability, the teacher adopts process assessment and conclusive assessment, the proportion of which is 60 to 40 . The process assessment is evaluated according to the preparation and publication of the conversational document, while the conclusive assessment generates a score based on the written test for the knowledge of Japanese.

3) The published criteria are as follows: Expression naturally 10 points; Use correct business etiquette 10 points; correct pronunciation and intonation are 10 points. Sound sonorous, intonation fluent 10 points; natural speed and rhythm 10 points; eye - and emotion-rich communication 10 points; ability to use appropriate communication strategies 10 points; be able to use body language properly. Words are basically accurate, meaning is basically complete 10 points; the use of media, team coordination of 10 points; total score is 100 points.

From the feedback of the students, the daily evaluation of the students' business Japanese study and the conclusive assessment results, the overall teaching effect is relatively ideal, indicating the expected teaching effect is achieved. Therefore, the project teaching method based on the concept of CDIO advanced education is an effective method suitable for the cultivation of practical talents and also suitable for Japanese classroom teaching.

\section{REFLECTION ON CDIO PROJECT TEACHING}

\section{A. Reflection on Teaching Methods}

The Project teaching method is focused on teaching language knowledge and developing the ability, with the purpose being to make students better to grasp the usage of the language and use language correctly and fluently. With real materials for teaching materials, the method is taking develop application ability as its teaching aim, advocating that teachers and students are supposed to participate together in classroom teaching, and students are required to take the initiative to learn, actively participate, while the teacher in the classroom teaching should be a demonstration performers, an organizer, a referee. The teacher's "teaching" role is to serve the students. As the English language teachers C, E, and Fekersley have said, "the most successful 
lesson are those where the majority of classroom activities are conducted by students rather than the teacher.".

Project teaching method is conducive to improving students' language application ability. It can gradually change from giving exclusive attention to knowledge in the past to emphasizing practical skills. It develops students' ability to acquire knowledge, apply knowledge, analyze problems and solve problems. However, it should be noted that some students find it difficult to adapt to the situation due to their different personalities and different knowledge bases. Some students with good expressive ability and strong expressive ability like this teaching method. They quickly transformed from passive recipients of knowledge to active participants of activities, showing great learning enthusiasm and initiative. However, some students showed obvious inadaptability. Obviously, these students believed that real teaching is a process when the knowledge is imparted by the teacher. It can be seen that no single teaching method is perfect and universal.

Traditional teaching method and project teaching method are not completely opposite in teaching method, teaching purpose and teaching process, and each has its own advantages. Therefore, they all have their own necessity and rationality in teaching, and the organic combination of them can be embodied in different teaching steps.

We should also pay attention to the method of evaluation in the teaching process. In the implementation process, the evaluation becomes an important link. Teachers should not only evaluate students' performance in a timely manner, but also encourage students to evaluate each other and give appropriate guidance during students' mutual evaluation. Evaluation is carried out in the manner of encouragement and correction, making evaluation a booster for students to improve their practical skills. In the evaluation, teachers must fully appreciate students' achievements to enhance students' confidence and the instructors should correct the defects or problems in students' oral Japanese application in time, and promote the development of students' communicative language towards accuracy, standardization, appropriateness and artistry.

\section{B. Reflection on Testing Methods}

As an integral part of language teaching, testing is not only a tool to assess the teaching effect, but also an important means to obtain teaching feedback. Besides, it also has an influence on students' attention to the teaching content and their attitude towards teaching, thus affecting the teaching effect. From this perspective, it is not enough to emphasize the reform of teaching methods, but also to reform the content and means of testing so that testing can truly serve its purpose.

The traditional language test breaks down the language into isolated "language points" to test students' mastery of language knowledge. The tests are still structured and accuracy is valued more than fluency and appropriateness. those test are usually in the form of multiple choice on the mastery of knowledge such as grammar, vocabulary and pronunciation. They often lack rich context and test only pieces of language knowledge too much, which consequently leads to the fact that teachers have to spend a lot of time teaching grammar knowledge in order to cope with such questions, thus neglecting the cultivation of the students ability to use language.

For modern Japanese teaching, testing should be on listening, speaking, reading and writing — four basic skills of comprehensive test, the purpose of which is to test students in different context the ability to use the language for effective communication. That is to say, the need for the language applicationcalls for observing students' practical ability of using language in real context, which provides, in the end, the evaluation of the level of language. Therefore, the change of teaching methods also requires the corresponding improvement of testing methods, so the author advocates that it is necessary to introduce applied tests vigorously. the most remarkable characteristics of an applied test is that it not only grasps the situation and how students' language knowledge grammar knowledge are transformed into grammatical ability, but also for the authenticity of language testing, more virtual or real communicative situations need to be created, mainly testing the examinee's ability to use language; the midterm and the final-grade-once-a-year way of testing should be avoided. at the same time to the proportion of daily examination should be raised to improve the effect of the teaching process.

\section{CONCLUSION}

To sum up, the project teaching method has great flexibility. It has a broad prospect and the possibility of effective implementation in China's teaching. It is also necessary to adapt to the new development of language, the new economic situation and the new changes of students. However, while the project teaching method is implemented, the traditional teaching method should not be abandoned. Only by adapting it to the current situation of foreign language teaching in China can it be adapted to the personnel training mode of current applied universities and be able to facilitate cultivating qualified personnel who have a solid language foundation and can communicate freely so as to lead Japanese teaching to a new stage.

\section{REFERENCES}

[1] Gu Peihua, Lu Xiaohua. CDIO outline and standard [M].Shantou university press, 2008

[2] Gao Yan. Application of project learning in the teaching of English linguistics, foreign language [J]. 2016. 6

[3] Zhang Lianmei. Application of project teaching method in college English teaching [J]. Chinese adult education Yukon. 2012. 11. 